\title{
Overexpression of a set of genes, including WISP-I, common to pulmonary metastases of both mouse DI 22 Lewis lung carcinoma and BI6-FI0.9 melanoma cell lines
}

\author{
O Margalit ${ }^{*, 1,2}$, L Eisenbach ${ }^{3}$, N Amariglio ${ }^{1,2}$, N Kaminski ${ }^{2}$, A Harmelin ${ }^{3}$, R Pfeffer ${ }^{4}$, M Shohat ${ }^{5}$, G Rechavi ${ }^{1,2}$ \\ and $\mathbf{R}$ Berger ${ }^{4}$
}

'Pediatric Hemato-Oncology, Safra Children's Hospital, Sheba Medical Center, Affiliated to Tel-Aviv University, Tel Hashomer 5262I, Israel; ' ${ }^{\text {Functional }}$ Genomics unit, Sheba Medical Center, Affiliated to Tel-Aviv University, Tel Hashomer 5262 I, Israel; ${ }^{3}$ Weizmann Institute of Science, PO Box 26 , Rehovot 76100, Israel; ${ }^{4}$ Institute of Medical Oncology and Radiotherapy, Sheba Medical Center, Affiliated to Tel-Aviv University, Tel Hashomer 52621, Israel; ${ }^{5}$ Department of Molecular Genetics, Felsenstein Medical Research Center, Rabin Medical Center, 14 Kaplan street, Petah-Tikva 49I 00, Israel

Despite advances in the management of solid tumours, the development of metastases continues to be the most significant problem and cause of death for cancer patients. To define genetic determinants of pulmonary metastases, we have applied oligonucleotide microarrays to established murine models of highly metastatic DI22 Lewis lung carcinoma and BI6-FI0.9 melanoma cell lines. These models are characterised by primary subcutaneous growth in C57BL/6) mice, a period of minimal residual disease and spontaneous pulmonary metastases. Microarray analysis defined seven genes, namely - arginase, brain natriuretic peptide (BNP), interleukin-I alpha (IL-I alpha), plasminogen activator inhibitor-2 (PAI-2), surfactant protein C (SP-C), uteroglobin (UG) and wnt-I-induced secreted protein-I (WISP-I), which were consistently elevated in pulmonary metastases compared to the primary tumour of both DI22 and BI6-FI 0.9 models. Previous studies demonstrated that two of these seven genes, IL-I alpha and PAI-2, are involved in the metastatic process. The results obtained by the microarrays were confirmed by real-time quantitative PCR, for three chosen genes PAI-2, WISP-I and UG. Our approach aimed to identify genes essential for the metastatic process in general and for pulmonary metastases specifically. Further research should address the precise role of these genes in the metastasising process to the lungs and test if they could be used as targets for future therapies.

British Journal of Cancer (2003) 89, 314-319. doi:10.1038/sj.bjc.6600977 www.bjcancer.com

(c) 2003 Cancer Research UK

Keywords: metastasis; WISP-I; DNA microarrays; Gene expression; DI22 Lewis lung carcinoma; BI6-FI0.9 melanoma

A crucial event during cancer progression is the switch from a locally growing tumour to a metastatic one. Tumour development and metastasis are complex processes that include transformation, proliferation, resistance to apoptosis, invasion, neovascularisation and metastatic spread (Liotta et al, 1991). Studies to identify molecules involved in tumour development and progression have resulted in the identification of a number of individual candidates that function as cell growth factors (Grandis et al, 1998), adhesion molecules (Van Waes et al, 1991, 1995), proteases (Andreasen et al, 2000 ), and cytokines that promote inflammation and angiogenesis (Chen et al, 1998, 1999).

The discovery of these molecules may be useful in developing new therapeutic interventions. For instance, synthetic Arg-Gly-Asp (RGD) containing peptides can disrupt integrin function (e.g., vitronectin receptor) and successfully inhibit both in vitro and in vivo melanoma cell invasion (Gehlsen et al, 1988).

\footnotetext{
*Correspondence: $\bigcirc$ Margalit, Pediatric Hemato-Oncology, Safra Children's Hospital, Sheba Medical Center, Affiliated to Tel-Aviv University, Tel Hashomer 5262I, Israel;

E-mail: ofer.margalit@sheba.health.gov.il

Received 20 September 2002; accepted 18 March 2003
}

Metastasis is a multiple-step process in which cancer cells leave the primary tumour site and relocate in a remote organ. This process involves interactions between cancer cells and their surrounding microenvironment. Tumours that metastasise do so to preferred target organs. To explain this apparent specificity, over 100 years ago, Paget formulated his 'seed and soil' hypothesis; that is, cells from a given tumour would 'seed' only favourable 'soil' in a target organ, one that supports colonisation for metastasis to occur.

Several studies used an in vivo selection scheme to select highly metastatic cell lines (Clark et al, 2000; Chen et al, 2001; Khanna et al, 2001). By analysing these cells on microarrays, gene expression patterns that correlate with progression to a metastatic phenotype have been defined. Clark et al (2000) have shown that the small GTPase RhoC enhances metastasis when overexpressed, whereas a dominant-negative Rho inhibits metastasis. Analysis of the phenotype of cells expressing dominant-negative Rho or RhoC indicates that RhoC is important in tumour cell invasion. The process of selecting highly metastatic cell lines, as done by Clark et al (2000), resulted in a large number of genes related solely to metastasis, but not to the microenvironmental changes in the preferred target organs.

To provide insight into mechanisms that allow tumours to metastasise specifically to the lungs, we searched for the genes 
coordinately overexpressed in pulmonary metastases of two distinct metastatic cell lines of different embryonic origin. The cell lines we used were the highly metastatic mouse D122 Lewis lung carcinoma and B16-F10.9 melanoma. We hypothesised that genes overexpressed in pulmonary metastases of both cell lines, might play a key role in both metastasis and homing of the metastasising cells, specifically to the lungs.

\section{MATERIALS AND METHODS}

\section{Mice and cell cultures}

Ten inbred male and female C57BL/6J mice, 12 weeks old, were grown and maintained in the animal facilities of the Weizmann Institute of Science and Tel-Aviv University. All animal experiments have been carried out with ethical committee approval. The ethical guidelines that were followed meet the standards required by the UKCCCR guidelines (Workman et al, 1998).

The highly metastatic D122 clone of the C57BL/6-derived Lewis lung carcinoma (Eisenbach et al, 1983) was maintained in DMEM supplemented with $10 \%$ heat-inactivated fetal calf serum, glutamine, combined antibiotics, sodium pyruvate and nonessential amino acids. The highly metastatic B16-F10.9 clone of the C57BL/ 6-derived malignant melanoma (Porgador et al, 1989) was grown in DMEM supplemented with $10 \%$ heat-inactivated fetal calf serum, glutamine and combined antibiotics.

The mice were divided into four groups. Groups 1 and 2, consisting of three mice each, male and female, respectively, were injected intra-footpad with $2 \times 10^{5} \mathrm{D} 122$ or B16-F10.9 cells/mouse, respectively. Groups 3 and 4, consisting of two mice each, male and female, respectively, served as a control. After 5 weeks, when primary tumours reached $\sim 0.8 \mathrm{~cm}$ in diameter, animals were anaesthetized and tumours were dissected and stored at $-80^{\circ} \mathrm{C}$. After an additional 4 weeks, lungs containing pulmonary metastases were dissected. The lungs of the mice in the control groups were dissected at the matching age. All specimens were snap-frozen in liquid nitrogen.

\section{Preparation of labelled cRNA}

Probe preparation was performed as recommended by the manufacturer of the microarrays (Affymetrix, 1998). Briefly, total RNA was isolated from pooled primary tumours and pooled lungs by homogenisation in ice-cold Trizol (Invitrogen). The RNA was then used as template for double-stranded cDNA synthesis with an oligo $(\mathrm{dT})_{24}$ primer containing a T7 RNA polymerase promoter site added to the $3^{\prime}$ end (Genset, La Jolla, CA, USA). The cDNA was extracted with phenol/chloroform, ethanol-precipitated, and used as a template for in vitro transcription (Ambion T7 Megascript system) with biotin-labelled nucleotides (Enzo Diagnostics). Labelled cRNA was fragmented and a hybridisation mix was generated as recommended (Affymetrix, 1998).

\section{Hybridisation of microarrays}

Aliquots of each sample ( $10 \mu \mathrm{g}$ cRNA in $200 \mu$ l hybridisation mix) were hybridised to a Genechip Hugene FL array. After hybridisation, each array was washed, stained with streptavidin phycoerythrin (Molecular Probes), washed again, hybridised with biotin labelled antistreptavidin phycoerythrin antibodies, restained with streptavidin phycoerythrin (Molecular Probes), and scanned (Hewlett-Packard, GeneArray scanner G2500A).

\section{Analysis of Genechip data}

Scanned output files were visually inspected for hybridisation artefacts and then analysed using Genechip ${ }^{\circledR} \quad 4.0$ software (Affymetrix). Arrays were scaled to an average intensity of 600 per gene and analysed independently. The expression value for each gene was determined by calculating the average of differences (perfect match intensity minus mismatch intensity) of the probe pairs in use for this gene. The expression analysis files created by Genechip $^{\mathrm{B}} 4.0$ software were then transferred to a database (Microsoft Access) linked to Internet genome databases (e.g. NHLBI, Swiss Prot and GeneCards) to update gene definitions. A value of 20 was assigned to all measurements lower than 20 . We did not include in the analysis genes that did not have at least one average difference intensity value $\geqslant 100$ which was defined as 'present' call by Affymetrix criteria. For cluster analysis, we used CLUSTER and TREEVIEW programs described by Eisen et al (1998). Fold ratios were calculated for each primary tumour against the pulmonary metastases of the same model and for the pulmonary metastases against the normal lung of the same gender. To ensure that the enhanced expression of genes in the pulmonary metastases was not due solely to the influence of the microenvironment, we removed genes with a higher level of expression in the normal murine lung compared to the pulmonary metastases. This criterion filtered 55, 78 and $91 \%$ of the genes that were otherwise considered as overexpressed in the D122, B16-F10.9 and both models, respectively.

\section{Real-time quantitative PCR analysis}

Relative quantitative PCR was performed using the LightCycler System ${ }^{\circledR}$ (Roche Diagnostics). An aliquot of $6 \mu \mathrm{g}$ of the previously extracted total RNA was reverse transcribed using Moloney Murine Leukemia Virus-Reverse Transcriptase (RT) and random hexamers as primer (Promega). The obtained cDNA was diluted $1 / 10$ with water and $5 \mu \mathrm{l}$ was used for amplification. The PCR was performed with the LightCycler FastStart DNA SYBR GreenI Kit (Roche Diagnostics) according to the protocol provided in the kit. To control for specificity of the amplification products, a melting curve analysis was performed. No amplification of unspecific products was observed. In addition, PCR products were gel separated to confirm a band of the expected size.

The relative initial amount of cDNA of a particular template in the cDNA mixture was extrapolated from a standard curve. The standards, composed of five serial dilutions of one of the cDNAs, ranging from $1 / 5$ to $1 / 1000$ of the original cDNA, were run in parallel with the samples under identical PCR conditions, amplified with the same set of primers. The slope of the standard curve was converted to the amplification efficiency $E$ by the following algorithm: $E=10^{-1 / \text { slope }}$. The primers used for all four genes - PAI-2, RhoC, WISP-1 and UG had an efficiency $>1.85$ (data not shown). The relative amounts obtained were normalised by the housekeeping gene beta-actin, whose levels of expression were not changed significantly according to the microarrays (data not shown). The detailed procedure for quantification has been described by Ginzinger (2002).

The primer sequences were $\left(5^{\prime}\right.$ to $\left.3^{\prime}\right)$ :

beta-actin - CTGAGAGGGAAATCGTGCG, GGTGGTACCACCA GACAAC;

PAI-2 - CTGCTACCCGAAGGTTCTG, GGAAGCAACAGGAG CATGC;

RhoC - GCTGGGCAAGAAGACTACG, CCTTCCTCAGATCGA ACCG;

WISP-1 - CGTGGAGCAACGGTATGAG, GAGAGTGAAGTTCG TGGCC;

UG - CATGCTGTCCATCTGCTGC, CTCTTGTGGGAGGGTATCC.

\section{RESULTS}

\section{Global analysis of gene expression}

Global analysis of gene expression reveals a correlation between the primary tumour of each model, D122 or B16-F10.9, to its 
matching pulmonary metastases. In other words, as expected, the diversity between the two models is greater than the diversity between the primary tumour and the pulmonary metastases of the same model. Only genes with at least one average difference intensity value $\geqslant 100$, which are defined as 'present' by Affymetrix criteria, were included in the cluster analysis (Figure 1).

\section{Oligonucleotide microarray analysis}

The tumour model described above was used with the highly metastatic mouse D122 Lewis lung carcinoma and B16-F10.9 melanoma cell lines. Microarray experiments examined differences in gene expressions between the subcutaneous primary tumour and the pulmonary metastases. We focus on the genes that were overexpressed in the pulmonary metastases compared to the primary tumour, since we assume that transcripts overexpressed in metastatic tissue have applicable diagnostic and therapeutic potential. Forty-two and 16 genes were overexpressed in pulmonary metastases derived from the mouse D122 and B16-F10.9 cell lines, respectively (Tables $1 \mathrm{a}$ and $\mathrm{b})$. Seven genes, namely arginase, brain natriuretic peptide (BNP), interleukin-1 alpha (IL-1 alpha), plasminogen activator inhibitor-2 (PAI-2), surfactant protein $\mathrm{C}$ (SP-C), uteroglobin (UG) and wnt-1-induced secreted protein-1 (WISP-1), were overexpressed in pulmonary metastases of both cell lines (Table 2).

We could not detect any consistent difference in the expression of RhoC in pulmonary metastases compared to the primary tumour. As this gene has been previously shown to be important in the metastatic phenotype of melanoma cell lines (Clark et al, 2000), we confirmed this microarray result using real-time quantitative PCR (RTQ-PCR) (Figure 2).

\section{RTQ - PCR confirms overexpression of PAI-2, WISP-1 and} UG in pulmonary metastases of both cell lines

To further investigate the reliability of our array data, we measured the expression levels of PAI-2, WISP-1 and UG that were overexpressed in both models using the LightCycler System ${ }^{\mathbb{R}}$ (Roche Diagnostics). The expression levels of PAI-2, WISP-1 and UG measured by RTQ - PCR were similar to those measured by the microarrays (Figure 3, UG data not shown).

\section{DISCUSSION}

Previous studies provided insight into the patterns of gene expression that allow tumours to metastasise by comparing highly

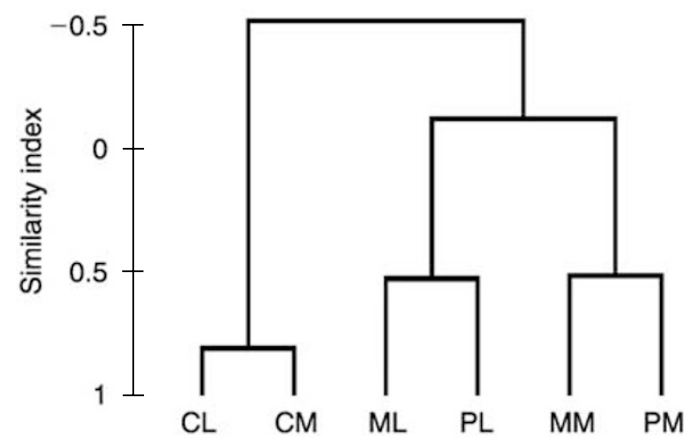

Figure I Dendrogram of cluster analysis of microarrays. $C L$, normal male murine lung - Control for the DI22 Lewis lung model; CM, normal female murine lung - control for the BI6-FI0.9 melanoma model; ML pulmonary metastases of the DI 22 Lewis lung model; $\mathrm{PL}$ - primary tumour of the DI22 Lewis lung model; MM - pulmonary metastases of the BI6FI0.9 melanoma model; PM - primary tumour of the B 16-FI0.9 melanoma model.
Table I Functional groups of genes that were overexpressed, at a fold $\geqslant 2.5$, in pulmonary metastases compared to primary tumour in the (a) DI22 model and (b) BI6-FI0.9 model

\begin{tabular}{ccc}
\hline Description & $\begin{array}{c}\text { GenBank } \\
\text { accession \# }\end{array}$ & $\begin{array}{c}\text { Fold } \\
\text { ratio }\end{array}$
\end{tabular}

(a) D/22 model

Apoptosis

Caspase $3^{\text {a }}$

miap-3

U54803

U88990

$\mathrm{MIHA}$

U36842

Cell adhesion

Integrin alpha $\vee(\mathrm{Cd} 5 \mathrm{I})^{\mathrm{a}}$

UI4I35

AB024538

Y07519

2.9

Islr

Lymphocyte antigen $84^{\mathrm{a}}$

5.2

Cellular matrix

Actin, alpha I

MI 2347

histone $\mathrm{H} 2 \mathrm{a}(\mathrm{A})-6 \mathrm{|}, \mathrm{H} 2 \mathrm{a}(\mathrm{B})-613$ and $\mathrm{H} 2 \mathrm{~b}-613(\mathrm{H} 2 \mathrm{~b}) \quad U 62673$

Differentiation

HI9

$\times 58196$

U60530

3.0

Madr2

ECM/angiogenesis

Collagen type VI, alpha 3 subunit

AF064749

Enamelin

Fibronectin

Matrilin-2 precursor ${ }^{\mathrm{a}}$

Procollagen type $X$, alpha I

082698

MI8194

U69262

$\times 67348$

9.7

0.1

4.5

4.0

Membrane and nuclear membrane

YEI/48

M25775

Metabolism

Acetyl coenzyme A dehydrogenase, long-chain ${ }^{a}$

U21489

$\mathrm{AKRICI3}$

Ferrochelatase

griPGHS

Pex

AB027/25

$M 61215$

M88242

U75646

Receptors/ligands

Bacteria binding macrophage receptor MARCO

UI8424

GRIPI

MIP2

$\times 53798$

Signal transduction

Mess $\left.\right|^{\text {a }}$

MPA

WSB-2

Transcription

maff $^{\mathrm{a}}$

AB009694

U79550

Slug, chicken homologue

A.224763

zinc finger gene OZF

AF043327

104280

10.8

$\mathrm{N}$-myristoyltransferase $2^{\mathrm{a}}$

Ribosomal protein (Rp/|2)

AFOI2129

AF093259

Dnmt2

$59-3.8$

homer-2a

U89352

$\times 56683$

Modifier 2 protein $^{\mathrm{a}}$

$\times 53619$

M72394

PLA2

Retinaldehyde-binding protein

SCID complementing gene $2^{\text {a }}$

AF084642

D78188

Sfrp2

Synaptobrevin-like protein

$\cup 8567$
$\times 96737$

(b) B/6-Fl 0.9 model

Apoptosis

P53-variant ${ }^{b}$

U59758 
Table I Continued

\begin{tabular}{|c|c|c|}
\hline Description & $\begin{array}{c}\text { GenBank } \\
\text { accession \# }\end{array}$ & $\begin{array}{l}\text { Fold } \\
\text { ratio }\end{array}$ \\
\hline \multicolumn{3}{|l|}{ ECM/angiogenesis } \\
\hline Hyaluronidase I & AFOII 567 & 5.8 \\
\hline Minopontin & $\times 13986$ & 8.7 \\
\hline VEGF-C & U73620 & 4.6 \\
\hline \multicolumn{3}{|l|}{ Metabolism/proteosome } \\
\hline beta-TrCP protein E3RS Ikappa B ${ }^{b}$ & AF099932 & 7.9 \\
\hline Ceramide glucosyltransferase & D89866 & 15.0 \\
\hline \multicolumn{3}{|l|}{ Signal transduction } \\
\hline cAMP-dependent Rap I & AFII5480 & 6.3 \\
\hline LIM and SH3 protein I & U58882 & 5.2 \\
\hline RAB7, member RAS oncogene familly & Y|336| & 2.8 \\
\hline \multicolumn{3}{|l|}{ Receptors/ligands } \\
\hline Mouse homologue of human ocular albinism I & $\times 98352$ & 2.7 \\
\hline \multicolumn{3}{|l|}{ Transcription/translation } \\
\hline Cyclin TI & AF095640 & 3.5 \\
\hline Myeloblastosis oncogene-like I & L3526। & 2.9 \\
\hline Zinc-finger protein 40 & D 10632 & 5.1 \\
\hline \multicolumn{3}{|l|}{ Other } \\
\hline HSP-I05 & L40406 & 2.5 \\
\hline Mouse Ig kappa chain V-region & MI8237 & 16.5 \\
\hline Potassium channel alpha subunit ${ }^{\mathrm{b}}$ & AF008574 & 2.9 \\
\hline
\end{tabular}

andicates genes that were underexpressed in the B|6-F|0.9 model. ${ }^{b}$ Indicates genes that were underexpressed in the DI22 model. Genes that were overexpressed in both models are not shown.

Table 2 Genes that were overexpressed, at a fold $\geqslant 2.5$, in pulmonary metastases compared to primary tumour in both DI22 and BI6-FI0.9 models

\begin{tabular}{|c|c|c|c|}
\hline \multirow[b]{2}{*}{ Description } & \multirow{2}{*}{$\begin{array}{c}\text { GenBank } \\
\text { accession \# }\end{array}$} & \multicolumn{2}{|c|}{ Fold ratio } \\
\hline & & DI22 model & FI0.9 model \\
\hline Arginase & U5। 805 & 22.5 & 4.9 \\
\hline BNP & DI6497 & 2.7 & 2.7 \\
\hline IL-I alpha & MI4639 & 3.1 & 7.9 \\
\hline PAI-2 & $\times 16490$ & 4.4 & 2.5 \\
\hline SP-C & AA921489 & 239.3 & 102.5 \\
\hline UG & L04503 & 383.6 & 27.7 \\
\hline WISP-I & AFI00777 & 3.7 & 4.5 \\
\hline
\end{tabular}

metastatic vs low metastatic cell lines. This approach identified genes that were overexpressed within the highly metastatic cell line and that were, in general, essential to the nonmetastatic/metastatic switch. One study using this approach demonstrated that the small GTPase RhoC was essential for the enhancement of melanoma metastasis when overexpressed. Furthermore, analysis of the phenotype of melanoma cells expressing dominant-negative Rho or RhoC indicated that $\mathrm{RhoC}$ is important in tumour cell invasion (Clark et al, 2000).

In this study, we could identify essential targets expressed within the tumour cell, as a result of interactions with the surrounding microenvironment. The reason for this is the comparison made between two phases of a tumour progression in vivo - the primary site and the metastases, both with the surrounding tissue, originating from a highly metastatic cell line. Our attitude aimed to emphasise genes that could be essential for metastasis to the lungs and might play a key role in homing the tumour cells specifically to that organ. Therefore, in our study, the small

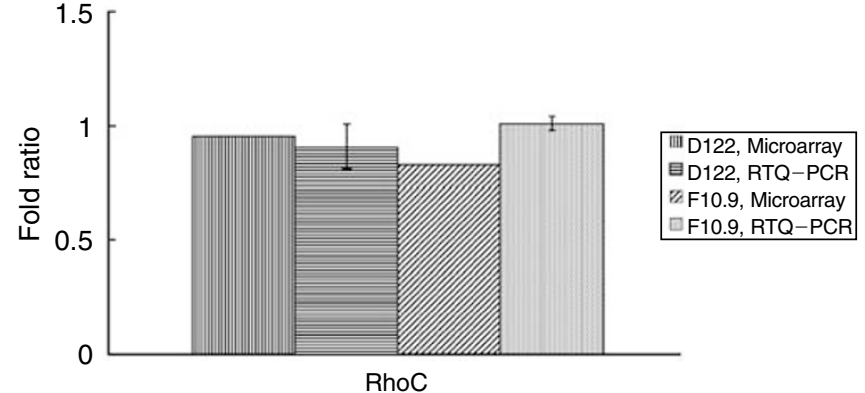

Figure 2 Comparative ratio analysis by RTQ-PCR and microarrays. Fold ratios were calculated for each primary tumour against the pulmonary metastases. RTQ $-P C R$ results (mean \pm s.d.) were obtained from three independent experiments, each in duplicate.

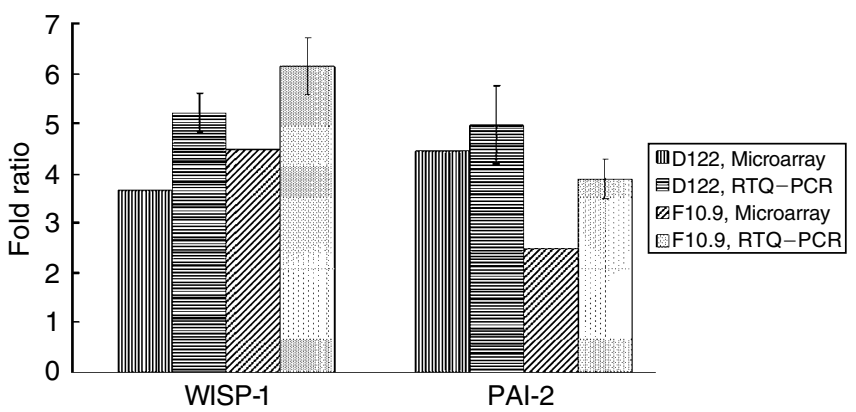

Figure 3 Comparative ratio analysis by RTQ-PCR and microarrays. Fold ratios were calculated for each primary tumour against the pulmonary metastases. RTQ-PCR results (mean \pm s.d.) for WISP-I and PAI-2 were obtained from three and four independent experiments, respectively, each in duplicate (PAI-2 results are illustrated by two representative experiments).

GTPase RhoC was not overexpressed in the pulmonary metastases compared to the primary tumour of both cell lines. We therefore argue that RhoC has general importance in tumour invasiveness and in the nonmetatstatic/metastatic switch, but not in the specific metastatic homing to the lungs.

Previously, Gemma et al (2001) compared the expression profiles of two subpopulations of an adenocarcinoma cell line with high metastatic potential - PC9/f9 and PC9/f14 - with the parent cell line PC9 using CDNA array. They have shown that the expression of matrix metalloproteinase-2 (MMP-2), plasminogen activator inhibitor-1 (PAI-1) and IL-1 alpha was overexpressed in the highly metastatic subpopulations. There is already abundant experimental evidence that the plasminogen activator system plays a key role in tumour invasion and metastasis (Andreasen et al, 1997; Schmitt et al, 1997). A critical balance of uPA, its cell surface receptor uPA-R (CD 87), and its inhibitor PAI-1 is the prerequisite for efficient focal proteolysis, adhesion and migration, and hence, subsequent tumour cell invasion and metastasis. There is evidence that PAI-2 may block uPA-mediated proteolysis and is inversely correlated with tumour progression of nonsmall cell lung carcinomas and neuroendocrine lung tumours (Robert et al, 1999) and breast cancer (Borstnar et al, 2002). In contrast, higher expression levels of PAI-2 were found in tumour tissues as compared to their normal equivalents and significant relations were found between PAI-2 and pathological stage in nonsmall cell lung cancer patients (Salden et al, 2000). Our data suggest a key role for PAI-2 in lung metastasis from different tumour origins.

Wnt-1-induced secreted protein (WISP-1) was identified by Pennica et al (1998) as an oncogene regulated by the Wnt-1-betacatenin pathway and is a member of the CCN family of growth factors, which are cysteine-rich, heparin-binding, secreted proteins associated with the extracellular matrix, and can interact with 
cellular integrins. Xu et al (2000) identified WISP-1 as betacatenin-regulated and its forced overexpression in normal rat kidney fibroblasts (NRK-49F) was sufficient to induce their transformation. Recently, it was shown that WISP-1 can both activate the anti-apoptotic Akt/PKB signalling pathway and act to block cell death in the p53-mediated apoptosis pathway ( $\mathrm{Su}$ et al, 2002).

Wnt-1-induced secreted protein-1 was overexpressed (2 to $>25$-fold) in $84 \%$ of human colon tumours examined compared with patient-matched normal adjacent mucosa (Pennica et al, 1998). The expression levels of WISP-1, in mammary tumours from Wnt-1 transgenic mice, were high in stromal fibroblasts lying within the fibrovascular tumour stroma, but low focally within tumour cells (Pennica et al, 1998). Elevated levels of WISP-1 in primary breast cancer were associated with more advanced features, such as tumour size and metastases to axillary lymph nodes (Xie et al, 2001).

In contrast, WISP-1 was found to be one of the 70 prognostic reporter genes able to identify clinical outcome in primary breast cancer patients. It was shown that WISP-1 was overexpressed in the good prognosis group of patients, who did not develop distant metastases within 5 years (Van't Veer et al, 2002). Furthermore, the mouse WISP-1 is identical to the gene identified as ELM1 (GenBank accession\# AB004873). ELM1 is expressed in low, but not high, metastatic mouse melanoma cells, and suppresses the in vivo growth and metastatic potential of $\mathrm{K}-1735$ mouse melanoma cells (Hashimoto et al, 1998). The contradiction between the above findings may be explained in view of previous studies suggesting that the effect of a single gene may differ according to the genetic and cellular context. For example, c-MYC can induce both cell proliferation and apoptosis (Evan et al, 1992; Jain et al, 2002; Pelengaris et al, 2002). Another example was given by Serrano et al (1997), who showed that the oncogene ras, known for its ability to transform immortal rodent cells to a tumourigenic state, can provoke premature cell senescence in primary human and rodent cells.

Here we have demonstrated overexpression of WISP-1 in pulmonary metastases of two distinct metastatic cell lines. We propose a key role for WISP-1 in the metastasising process to the lungs.

Interleukin-1 alpha was shown to enhance the adhesion of A549 lung carcinoma and M6 melanoma cells to the vascular surface both in vitro and in vivo, suggesting that IL-1 proteins facilitate the metastatic process (Lauri et al, 1990). Significant correlation between expression of IL-1 alpha and liver metastasis in gastric carcinoma was shown (Tomimatsu et al, 2001), suggesting that IL-1 alpha functions universally in the metastatic process. Here we have demonstrated overexpression of IL-1 alpha in pulmonary metastases of two distinct metastatic cell lines.

Arginase converts L-arginine to L-ornithine, which is the precursor of polyamines that are essential components of cell proliferation. $N$-hydroxy-L-arginine (NOHA), a stable intermediate product formed during conversion of L-arginine to $\mathrm{NO}$ by nitric oxide synthase, inhibited proliferation of the high arginaseexpressing MDA-MB-468 cells, activated caspase- 3 and induced apoptosis after $48 \mathrm{~h}$ (Singh et al, 2000). Additionally, Chang et al (2001) have shown that arginase induction in macrophages can enhance tumour cell growth by providing them with polyamines and suppress tumour cytotoxicity by reducing NO production. The arginase inhibitor L-norvaline downregulated this proliferative effect. Yet, an active subunit of arginase was found to inhibit differentially poorly liver metastasizing cell lines (Cavanaugh and Nicolson, 2000). Highly metastatic cells displayed no ability to preferentially inactivate or inhibit the activity of arginase, but they did display slightly greater amounts of intracellular arginine. Here, however, arginase was overexpressed in pulmonary metastases of two distinct metastatic cell lines. Therefore, arginase may be essential for tumour metastasis to the lungs, but not to the liver, and lung macrophages might take part in that process.

Brain natriuretic peptide (BNP) is a polypeptide hormone, demonstrated mainly in the heart, which causes vasodilation and natriuresis in man and animals. Elevated levels of BNP are usually associated with cardiac dysfunction (Cowie and Mendez, 2002). There is also evidence that human small cell lung cancer cell lines produce BNP (Ohsaki et al, 1999). There is no known connection of BNP to tumourigenesis or metastasis.

Uteroglobin (UG) was found to be infrequently expressed in non-small cell lung cancer cell lines, despite being abundantly produced by progenitor cells for normal and neoplastic airway epithelium. A549 cells transfected with UG demonstrated a marked reduction in invasiveness and decreased adhesiveness to fibronectin compared with the controls (Szabo et al, 1998). Surfactant-C (SP-C) is overexpressed in normal lungs and plays an important role in its functioning. Our data show overexpression of UG and SP-C in pulmonary metastases compared to both primary tumours and normal lung. Nevertheless, these genes were also overexpressed in the normal lung compared to the primary tumour.

Most of the previously described genetic alterations in various cancers involve inactivation of tumour suppressor genes. The proteins produced from these genes are difficult to target with drugs, because they are inactive or absent in the cancer cells. In contrast, enzymes whose expression is elevated in cancer cells like those encoded by WISP-1, arginase, IL-1 alpha and PAI-2 provide excellent targets for drug discovery purposes. Further research should address the specific role of these genes in the formation of pulmonary metastases from different tumours.

\section{ACKNOWLEDGEMENTS}

This work was supported by the Arison Family. G. Rechavi holds the Gregorio and Dora Shapiro Chair in Hematologic Malignancies at the Sackler Faculty of Medicine, Tel-Aviv University, Tel-Aviv, Israel. This work was performed in partial fulfillment of the requirements for a Ph.D. degree of Ofer Margalit, Sackler Faculty of Medicine, Tel-Aviv University, Tel-Aviv, Israel.

\section{REFERENCES}

Affymetrix (1998) Eukaryotic Expression Analysis Target Preparation. Santa Clara, CA: Affymetrix

Andreasen PA, Egelund R, Petersen HH (2000) The plasminogen activation system in tumor growth, invasion, and metastasis. Cell Mol Life Sci 57: $25-40$

Andreasen PA, Kjöller L, Christensen L, Duffy MJ (1997) The urokinasetype plasminogen activator system in cancer metastasis: a review. Int $J$ Cancer 72: $1-22$

Borstnar S, Vrhovec I, Svetic B, Cufer T (2002) Prognostic value of the urokinase-type plasminogen activator, and its inhibitors and receptor in breast cancer patients. Clin Breast Cancer 3: 138-146
Cavanaugh PG, Nicolson GL (2000) Partial purification of a liver-derived tumor cell growth inhibitor that differentially inhibits poorly-liver metastasizing cell lines: identification as an active subunit of arginase. Clin Exp Metastasis 18: 509-518

Chang CI, Liao JC, Kuo L (2001) Macrophage arginase promotes tumor cell growth and suppresses nitric oxide-mediated tumor cytotoxicity. Cancer Res 61: $1100-1106$

Chen JJ, Peck K, Hong TM, Yang SC, Sher YP, Shih JY, Wu R, Cheng JL, Roffler SR, Wu CW, Yang PC (2001) Global analysis of gene expression in invasion by a lung cancer model. Cancer Res 61: $5223-5230$ 
Chen Z, Colon I, Ortiz N, Callister M, Dong G, Pegram MY, Arosarena O, Strome S, Van Waes C (1998) Effects of IL-1 $\alpha$, IL-1RA and neutralizing antibody on proinflammatory cytokine expression by human squamous cell carcinoma lines. Cancer Res 58: $3668-3676$

Chen Z, Malhotra PS, Thomas GR, Ondrey FG, Duffey DC, Enamorada I., Mousa S, Van Waes C (1999) Expression of proinflammatory and proangiogenic cytokines in human head and neck patients. Clin Cancer Res 5: $1369-1379$

Clark EA, Golub TR, Lander ES, Hynes RO (2000) Genomic analysis of metastasis reveals an essential role for RhoC. Nature 406: 532-535

Cowie MR, Mendez GF (2002) BNP and congestive heart failure. Prog Cardiovasc Dis 44: $293-321$

Eisen MB, Spellman PT, Brown PO, Botstein D (1998) Cluster analysis and display of genome-wide expression patterns. Proc Natl Acad Sci USA 95: $14863-14868$

Eisenbach L, Segal S, Feldman M (1983) MHC imbalance and metastatic spread in Lewis lung carcinoma clones. Int J Cancer 32: 113-120

Evan GI, Wyllie AH, Gilbert CS, Littlewood TD, Land H, Brooks M, Waters CM, Penn LZ, Hancock DC (1992) Induction of apoptosis in fibroblasts by c-myc protein. Cell 69: $119-128$

Gehlsen KR, Argraves WS, Piersbacher MD, Ruoslahti E (1988) Inhibition of in vitro cell invasion by Arg-Gly-Asp-containing peptides. J Cell Biol 106: $925-930$

Gemma A, Takenaka K, Hosoya Y, Matuda K, Seike M, Kurimoto F, Ono Y, Uematsu K, Takeda Y, Hibino S, Yoshimura A, Shibuya M, Kudoh S (2001) Altered expression of several genes in highly metastatic subpopulations of a human pulmonary adenocarcinoma cell line. Eur J Cancer 37: $1554-1561$

Ginzinger D (2002) Gene quantification using real-time quantitative PCR: an emerging technology hits the mainstream. Exp Hematol 30: 503-512

Grandis JR, Melhem MF, Gooding WE, Day R, Holst VA, Wagener MM, Drenning SD, Tweardy DJ (1998) Levels of TGF- $\alpha$ and EGFR protein in head and neck squamous cell carcinoma and patient survival. J Natl Cancer Inst 90: 824-832

Hashimoto Y, Shindo-Okada N, Tani M, Nagamachi Y, Takeuchi K, Shiroishi T, Toma H, Yokota J (1998) Expression of the Elm1 gene, a novel gene of the CCN (connective tissue growth factor, Cyr61/Cef10, and neuroblastoma overexpressed gene) family, suppresses In vivo tumor growth and metastasis of K-1735 murine melanoma cells. I Exp Med 187: $289-296$

Jain M, Arvanitis C, Chu K, Dewey W, Leonhardt E, Trinh M, Sundberg CD, Bishop JM, Felsher DW (2002) Sustained loss of a neoplastic phenotype by brief inactivation of MYC. Science 297: 102-104

Khanna C, Khan J, Nguyen P, Prehn J, Caylor J, Yeung C, Trepel J, Meltzer P, Helman L (2001) Metastasis-associated differences in gene expression in a murine model of osteosarcoma. Cancer Res 61: 3750-3759

Lauri D, Bertomeu MC, Orr FW, Bastida E, Sauder D, Buchanan MR (1990) Interleukin-1 increases tumor cell adhesion to endothelial cells through an RGD dependent mechanism: in vitro and in vivo studies. Clin Exp Metastasis 8: 27 -32

Liotta LA, Steeg PS, Stetler-Stevenson WG (1991) Cancer metastasis and angiogenesis: an imbalance of positive and negative regulation. Cell 64: $327-336$

Ohsaki Y, Gross AJ, Le PT, Oie H, Johnson BE (1999) Human small cell lung cancer cells produce brain natriuretic peptide. Oncology 56: 155-159

Pelengaris S, Khan M, Evan GI (2002) Suppression of Myc-induced apoptosis in beta cells exposes multiple oncogenic properties of Myc and triggers carcinogenic progression. Cell 109: 321 - 334

Pennica D, Swanson TA, Welsh JW, Roy MA, Lawrence DA, Lee J, Brush J, Taneyhill LA, Deuel B, Lew M, Watanabe C, Cohen RL, Melhem MF, Finley GG, Quirke P, Goddard AD, Hillan KJ, Gurney AL, Botstein D,
Levine AJ (1998) WISP genes are members of the connective tissue growth factor family that are up-regulated in wnt-1-transformed cells and aberrantly expressed in human colon tumors. Proc Natl Acad Sci USA 95: $14717-14722$

Porgador A, Feldman M, Eisenbach L (1989) H-2Kb transfection of B16 melanoma cells results in reduced tumorigenicity and metastatic competence. J Immunogenet 16: $291-303$

Robert C, Bolon I, Gazzeri S, Veyrenc S, Brambilla C, Brambilla E (1999) Expression of plasminogen activator inhibitors 1 and 2 in lung cancer and their role in tumor. Clin Cancer Res 5: 2094-2102

Salden M, Splinter TA, Peters HA, Look MP, Timmermans M, van Meerbeeck JP, Foekens JA (2000) The urokinase-type plasminogen activator system in resected non-small-cell lung cancer. Ann Oncol 11: $327-332$

Schmitt M, Harbeck N, Thomssen C, Wilhelm O, Magdolen V, Reuning U, Ulm K, Höfler H, Jänicke F, Graeff H (1997) Clinical impact of the plasminogen activation system in tumor invasion and metastasis: prognostic relevance and target for therapy. Thromb Haemost 78: $285-296$

Serrano M, Lin AW, McCurrach ME, Beach D, Lowe SW (1997) Oncogenic ras provokes premature cell senescence associated with accumulation of p53 and p16INK4a. Cell 88: 593-602

Singh R, Pervin S, Karimi A, Cederbaum S, Chaudhuri G (2000) Arginase activity in human breast cancer cell lines: $N$ (omega)-hydroxy-L-arginine selectively inhibits cell proliferation and induces apoptosis in MDA-MB468 cells. Cancer Res 60: 3305-3312

Su F, Overholtzer M, Besser D, Levine AJ (2002) WISP-1 attenuates p53mediated apoptosis in response to DNA damage through activation of the Akt kinase. Genes Dev 16: $46-57$

Szabo E, Goheer A, Witschi H, Linnoila RI (1998) Overexpression of CC10 modifies neoplastic potential in lung cancer cells. Cell Growth Differ 9: $475-485$

Tomimatsu S, Ichikura T, Mochizuki H (2001) Significant correlation between expression of interleukin-1 alpha and liver metastasis in gastric carcinoma. Cancer 91: 1272-1276

Van Waes C, Kozarsky KF, Warren AB, Kidd L, Paugh D, Liebert M, Carey TE (1991) The A9 antigen associated with aggressive human squamous carcinoma is structurally and functionally similar to the newly defined integrin $\alpha 6 \beta 4$. Cancer Res 51: $2395-2402$

Van Waes C, Surh DM, Chen Z, Rhim JS, Brager R, Roy SB, Kashima H, Wolf GT, Carey TE (1995) Increase in suprabasilar integrin adhesion molecule expression in human epidermal neoplasms accompanies increased proliferation occurring with immortalization and tumor progression. Cancer Res 55: 5434-5444

Van't Veer LJ, Dai H, van de Vijver MJ, He YD, Hart AA, Mao M, Peterse HL, van der Kooy K, Marton MJ, Witteveen AT, Schreiber GJ, Kerkhoven RM, Roberts C, Linsley PS, Bernards R, Friend SH (2002) Gene expression profiling predicts clinical outcome of breast cancer. Nature 415: $530-536$

Workman P, Twentyman P, Balkwill F, Balmain A, Chaplin D, Double J, Embleton J, Newell D, Raymond R, S, Stephens T, Wallace J (1998) United Kingdom Co-ordinating Committee on Cancer Research (UKCCCR) Guidelines for the Welfare of Animals in Experimental Neoplasia. Br J Cancer 77: 1 - 10

Xie D, Nakachi K, Wang H, Elashoff R, Koeffler HP (2001) Elevated levels of connective tissue growth factor, WISP-1, and CYR61 in primary breast cancers associated with more advanced features. Cancer Res 61: $8917-8923$

$\mathrm{Xu} \mathrm{L}$, Corcoran RB, Welsh JW, Pennica D, Levine AJ (2000) WISP-1 is a Wnt-1- and beta-catenin-responsive oncogene. Genes Dev 14: $585-595$ 